\title{
BRUCELLOSIS IN CHILDREN
}

\author{
BY \\ P. W. BOTHWELL \\ From the Department of Public Health, Bristol
}

(RECEIVED FOR PUBLICATION APRIL 16, 1962)

\section{1: Review of British and American Work}

Published British work on childhood brucellosis has not been extensive. Williamson and Gibson (1931) described the first case in an infant aged 20 months. Since then only three series of childhood brucellosis have been published, forming part of a series of cases of all ages (Beattie, Smith and Tulloch, 1935; Smith, 1951 ; Dalrymple-Champneys, 1960). A series of eight mild cases in childhood has been described by Paterson and Hardwick (1938). Elkington, Wilson, Taylor and Fulton (1940) and Cruickshank and Stevenson (1942) have described mild outbreaks of brucellosis in schoolchildren. Dalrymple-Champneys has referred to childhood cases in his various intermediate papers $(1950,1952)$.

In the two largest series, the childhood cases constituted $2.8 \%$ (Smith, 1951) and 10.3\% (Dalrymple-Champneys, 1960), both series giving a rate of about 32 cases of all ages per million of the population. The low proportion of childhood cases corresponds to American findings: Spink (1956) reported an incidence of $2.5 \%$ in children.

Wallis (1959) estimated the incidence of childhood brucellosis to be $1 \%$ of hospital patients, based on observation of 3,000 paediatric cases seen over five years. His monograph describes in detail the clinical and epidemiological factors in 35 patients considered to have brucellosis and his are the only recent papers on childhood brucellosis in this country.

In the United States, Jordan (1945) found a specific overall rate of reported cases to be 0.9 per 100,000 in rural children and 0.4 in urban children, compared with 1.4 in urban housewives. Jordan further stated (1950) that $8.8 \%$ of all cases in a noncontact series were in children under 14 years of age compared with $4.3 \%$ in a contact series.

A low percentage of children was also found by Magoffin, Kabler, Spink and Fleming (1949), only $3.1 \%$ of 3,315 cases being children under 10 years. When contact cases were excluded, however, the proportion of childhood cases increased, and in 74 proven cases with no animal contact nearly $10 \%$ were children under 10 years.

Hagebusch and Frei (1941) had previously concluded that the disease was common but self-limited in childhood and that spontaneous recovery masked the real incidence. Of 182 cases of childhood brucellosis diagnosed by them, six were classified as acute and 176 as chronic; $95 \%$ were under 6 years of age and $65 \%$ were female, corresponding with their experience of adult cases in St. Louis, where at that time $78 \%$ of over 1,000 cases had been female. A male preponderance of cases has usually been found in other studies, e.g. Dalrymple-Champneys' series of 150 children $(1.94: 1$, M. : F.). Spink (1952), in 253 childhood cases, found 168 boys to 85 girls and Wallis (1959) reported the disease in 19 boys and 16 girls.

The apparent scarcity of childhood cases has been attributed to various factors. Garrod (1937) found that Brucella was more easily killed by hydrochloric acid than any of the other pathogenic organisms and considered that this might account for the low pathogenicity of brucellosis for the human subject generally. The acidity of gastric juice in children is less than that of adults. Mean values of acidity (free acidity degrees) are given by Behrendt (1949) and vary from mean rates of $12 \cdot 5$ between 2 and 10 years to 49 at age 20. So with less free acid than the adult, the child might be expected to be less able to destroy the brucella. On the other hand, what he has may be counted on and the adult might more often have achlorhydria.

Hall (1950) observed that the blood serum of infants of 3 months or less was strongly bactericidal for $B r$. abortus, that two-thirds of infants between 4 and 16 months had serum with little or no bactericidal activity, but that in children over 18 months, as well as in normal adults, strong bactericidal action against $\mathrm{Br}$. abortus was shown by the serum. He concluded that the protection of young infants was due to passive antibodies from the mother, but could not thereby explain the bactericidal 
powers of serum in later life. Lovell (1951), arguing from experience of resistance to infection in young animals, including man, suggested that the non-susceptibility was due to lack of suitable soil for growth of the organism before puberty. Huddleson (1952) showed that normal bovine serum, in the presence of sulphadiazine and added complement, inhibited the growth of Br. abortus. A Brucella growth-inhibiting factor was not demonstrated in the serum of newborn calves before ingestion of colostrum; after colostrum the inhibition of Br. abortus was higher, but not greater than in normal adult serum. This factor was not connected with the $\gamma$ globulin content of the serum. Spink (1956) considered, however, that protection was afforded in children by intact tonsils and that the dilution of the organisms in milk would reduce the chance of infection for children compared with the more likely contact infection for the adult. McCullough (1955), on the other hand, has referred to the simple lack of detection of childhood brucellosis, since in this group blood serum tests are less likely to be carried out. This would be in accord with Debono's (1943) reference to the fact that brucellosis in Malta (Br. melitensis) was more frequent in children under 5 than in any other age up to 25 years.

The physiological and metabolic factors responsible for resistance of young children to brucellosis are therefore not exactly known. Calves of 3-9 months are much more resistant to brucellosis than mature heifers. S.19 vaccination of calves under 6 months does not produce immunity (McDiarmid, 1960). Kids and lambs appear more resistant than older animals, but weanlings and suckling pigs are more susceptible than the young of other animal species commonly infected.

Dooley (1931) concluded, from the published material on undulant fever, that little was known about infection in childhood, but a study of agglutination reactions in young children who had been drinking raw milk suggested that they were relatively insusceptible to the disease. The finding of Angle, Algie, Baumgartner and Lunsford (1938) that $9 \%$ of 7,122 children in Kansas City were positive to intradermal brucellin, with an increasing percentage of reactors going up the age scale to early adulthood, showed that the infection rate was continuing quite high. In Angle's study, $79 \cdot 3 \%$ of all positive reactors were raw milk drinkers. Russell (1947) found that, of 141 children with tissue immunity, $123 \mathrm{had}$ had a vague illness suggestive of the disease.

A similar spread of infection without clinical manifestations has been shown in the various family studies of brucellosis. Dalrymple-Champneys (1960) found only nine instances of more than one clinical case in a family, the intervals between the infections ranging from two days to 18 months. Spink (1954), in 16 years of extensive epidemiological and clinical studies, found only nine families in which additional information of human infection was obtained; although evidence of infection was present in 17 additional individuals coming from these nine families, in no instance was there more than one additional case of illness in a family.

Recently, one interesting example of a family multiple infection, which appears to have been due to Br. abortus, has been recorded in this country (R. C. McLeod, 1960, personal communication). Six members of a family (including children aged 11,10 and 8 years) fell ill between October 1957 and March 1960. The symptoms included erythematous rashes, swollen joints, pains in abdomen and buttocks, and lymphadenopathy; positive titres to $\mathrm{Br}$. abortus were recorded in all these cases. In May 1958 an abortion storm, affecting 16 of 28 cows, occurred in the herd from which raw milk was supplied to the family. All the milk routinely went for pasteurization except one bottle taken home by a man who worked on the farm at week-ends.

Wallis $(1957,1959)$ confirms that childhood cases are very easily missed, and he refers to a great variety of presentations and complications associated with childhood brucellosis.

Complications of the childhood disease reported in this country are: meningitis (Broadbent, 1931; Black, 1937); meningitis with ocular palsy and with pyuria and urticaria (Leys, 1943); arthritis of knee and shoulder (Beattie et al., 1935); and intermittent epistaxis (Branwood, 1952). Wallis (1957, 1959) has described cases presenting as miliary tuberculosis, spinal radiculitis and tuberculous rheumatism. From the United States, Hagebusch and Frei (1941) presented evidence for transfer of a maternal infection to a child in utero or in the process of delivery; they referred to five women with the disease who presented with sterility as one of their complaints, and to the review by Cozzolino (1915) of 48 cases of brucellosis in which arrested development and some degree of mental deficiency followed the infection in infancy. So far as is known, similar findings have not been reported elsewhere. McCullough (1955) has referred to the fact that peripheral neuritis, commonly sciatic, suppurative arthritis, monoarticular arthritis, cold abscess and osteomyelitis are common in childhood cases; bronchopneumonia has, he states, been 
reported, but endocarditis and cirrhosis of the liver, which have been frequently described in adults, have not been reported in children. Hepatitis and jaundice have been described in childhood as well as ocular inflammatory lesions (Dalrymple-Champneys, 1960). The two fatal childhood cases reported by Dalrymple-Champneys, aged 8 years and 21 months, had intestinal haemorrhage with jaundice in one case, and enlarged liver and spleen with abdominal distension in the other.

In all the British series of childhood cases, infection has mainly been attributed to raw milk, although in the U.S.A. Spink (1956) is inclined to the view that the exploratory habits of children in the country might readily lead them into contact with infected material in the vicinity of farms. Renoux (1953) considers that the resistance shown by children is only apparent and results from the lack of close contact between children and infected animals or to the fact that the young are rarely fed on raw milk; when such conditions have occurred, he has noted that the susceptibilities of children or infants are the same as those of adults.

Blood Picture. Most authorities (Huddleson, 1943; Castaneda and Guerrero, 1946; Spink, 1956; Dalrymple-Champneys, 1960) describe leucopenia or normal total W.B.C. counts with relative or absolute lymphocytosis. The W.B.C. total rarely exceeds 20,000 and is usually nearer 10,000 (Dalrymple-Champneys, 1960). 'Pathologic lymphocytes' and 'liver damage' cells have been described by Munger and Huddleson (1939). Sabin (1923) reported increased monocytes of a type associated with various kinds of hepatic damage and similar to atypical monocytes found with infective hepatitis. In this connexion, Braude (1955) showed that even in uncomplicated cases of brucellosis there was microscopic evidence for the existence of granulomata in sections of the liver and bone marrow and he pointed out that these microscopic lesions were present in enormous numbers in many tissues in brucellosis. Clearly such lesions in the liver would account for the liver damage cells and the abnormal mononuclear picture. This similarity in the reaction of the reticulo-endothelial system to some viruses and rickettsia on the one hand and to brucella on the other, reflects also the virus-like intracellular multiplication ability of brucellae. It would be intriguing if some glandular fevers, where reliance was placed on the differential and morphological white blood film, were in fact brucellosis. In view of the frequent lymphadenopathy which has been reported in brucellosis (Conway, 1949), this seems a real possibility. The possible confusion of the W.B.C. differential and morphology in brucellosis with glandular fever has been referred to by Rubenstein and Shaw (1944). The lymphocytic response has been described by Calder, Steen and Baker (1939) as a lymphocytic 'shift to the left' with an unusually high number of immature lymphocytes.

In Br. melitensis infection, Munger (1941) found leucopenia with relative lymphocytosis and slight monocytosis. Rainsford (1933) had found, in studying brucella infection in Malta, that a similar increase in mononuclears indicated a good prognosis, while early stages of the disease showed a deficiency of mononuclears.

Agglutination and Culture. The interpretation of positive serum agglutinin titre levels in brucellosis has been much discussed. From all that has been written, it may be stated that probably any titre from even 1/10 upwards, in the presence of clinical evidence of the disease, is of significance, and the higher the titre with clinical symptoms, the greater the significance. On the other hand, very high titres exist without current or past known history of symptoms-a titre as high as one in several thousands can exist without clinical disease; consequently, to accept any arbitrary titre of, say, $1 / 80$ or $1 / 100$, as diagnostic is unwarranted, while only a low titre may be demonstrable in persons who have undoubted clinical brucellosis. No agglutinins or low and absent agglutinins in bone brucellosis with cultured organisms from lesions are reported by Kelly, Martin, Schirger and Weed (1960) at the Mayo Clinic. A rising titre with clinical symptoms and signs is of course highly suggestive. The United States Committee on Public Health Aspects of Brucellosis (J. Amer. med. Ass., 1954) suggested a titre of $1 / 320$ as diagnostic. Wilson, Dalrymple-Champneys, Spink and others appear to consider $1 / 100$ as being sufficiently high for a diagnosis in the presence of other indications.

In children, the Coombs test (Wilson and Merrifield, 1951) might be useful as a routine in suspected childhood cases. The immune reaction of the child may differ from that of the adult, and incomplete and normally undetectable antibodies may be produced, and these may be more effective against brucellae than the complete antibodies detectable by the usual tube test. So far as is known, no figures are available to show the comparative incidence of blocking antibodies in childhood compared with adult serum. Elberg (1958) 
has outlined procedures that might be followed in testing for incomplete blocking type antibodies, but says that when the normal tube test is carried out properly many difficulties formerly reported are obviated; however, he still leaves room for a technique to allow for incomplete or blocking antibodies. The papers of Bürki and Fey (1953), Hall and Manion (1953), Wagner and Kuhns (1953) and Cruickshank (1956) add support to the view that the blocking antibody test should be in routine use on serum negative to the tube test, or alternatively that an appropriate technique to allow for blocking antibodies should be in use with the tube test. Zinneman, Glenchur and Hall (1959) say that blocking antibodies appear later than the agglutinating antibodies; they appear first on the $\gamma$ globulins, but shift to the $\beta$ globulins and persist after agglutinating antibodies subside.

Blood culture is, of course, the definite diagnostic measure, but only a low percentage of results are positive even when systematic attempts are made (Spink, 1956). Often blood culture is not tried when the agglutination is positive, and so in many cases it is never attempted at all. If blood culture positive cases only were accepted as true cases of brucellosis in this country, very few indeed would be authenticated. Of Dalrymple-Champneys' cases, $3 \%$ had positive blood culture, while blood culture recoveries sent for strain typing at the Brucellosis Reference Laboratory account for only $3 \%$ of Public Health Laboratory Service cases. Marrow, spleen, liver or gland puncture, followed by microscopy and culture, can establish the diagnosis if culture is positive, and if granulomata are present they can be suggestive though not pathognomonic. It is, of course, unlikely that these manoeuvres would be resorted to in mildly ill patients. The most likely way to improve the frequency of diagnosis and its accuracy, therefore, seems to lie in ensuring that the tube test is carried out correctly and that the technique followed allows for the detection of incomplete or blocking antibodies. The W.H.O. Expert Committee (World Health Organization, 1951, 1953, 1958) has devoted considerable space to the need to standardize the antigen used in the tube test. It is of importance to note, therefore, that the antigen used by the Public Health Laboratory Service and that used by the Ministry of Agriculture and the Agricultural Research Council (WHO/FAO antigen) appear to be of different sensitivity, and a reading of $1 / 10$ on the WHO/FAO antigen appears to be equivalent to at least $1 / 80$ on the Public Health Laboratory Service material. Thus the need exists to standardize these materials in order to achieve comparable results.
Skin Manifestations. Skin manifestations of brucellosis appear to be quite common and varied in type. In Dalrymple-Champneys' series 126 cases had rashes, the commonest being erythematous (15) or a roseolar type resembling the rose spots of typhus (14); 15 other varieties of skin rashes were reported in his series (1960). Spink (1956) reported dermatological abnormalities in less than $5 \%$ of cases. These rashes were mainly erythematous in type, and one simulated lupus erythematosus. The distinctive skin eruptions seen in veterinarians have been noted by many authors. These are allergic reactions to brucella organisms contacted in vaginal manipulations in cows and are not likely to be observed in children. Herpetiform and purpuric lesions, pigmentation and loss of hair have also been described.

Skin Tests in Brucellosis. Since Burnet (1922) reported the tuberculin-like reaction to intradermal $B r$. melitensis filtrate, it has become clear that several problems are involved, viz. achieving specificity for brucellosis, strain specificity to $B r$. abortus, $B r$. melitensis and $B r$. suis, ability to diagnose recent infection and to obtain a non-agglutinogenic skin allergen.

Specificity of the test for brucellosis is accepted. A strain-specific allergen is not in general use, though Pennell and Huddleson (1937) attributed this ability to an endo-antigen tested on animals.

Positive skin tests do not differentiate recent or old infection (Meyer, 1950). Nor is a positive test diagnostic in the absence of clinical symptoms.

The effect of brucellergens in causing only transient elevation in antibody in persons not previously sensitized (i.e. previously infected) and a longstanding elevation in persons who have been sensitized (whether initial skin test negative or positive) has been used by Barrett and Rickards (1953) and Davies (1957) as a diagnostic measure. Spink (1956) on the other hand has eschewed the skin test as a diagnostic weapon in his clinic.

Skin test, blood culture and serum agglutination test results are frequently at variance. A nonantigenic extract of Br. abortus (PEBA) was reported on by Ottosen and Plum (1949). Neither agglutinins nor complement-fixation antibodies were elicited in rabbits; but $0.05 \mathrm{ml}$. intradermal doses showed conspicuous allergic reactions in brucella-infected guinea-pigs, and practically no reactions in normal guinea-pigs or in guinea-pigs previously exposed to PEBA. These findings were largely confirmed in cattle. PEBA appears to be an amphoteric compound containing tyrosin.

Meyer (1950), reviewing 82 papers on brucella 
skin testing, considers that the basic studies of Miles and Pirie (1939) in this country on antigens for intradermal tests, and including quantitative evaluation of the reaction, should receive more attention. He considers that a suitable brucella antigen, standardized technique and interpretation, should be systematically worked out by reliable immunologists.

Wallis (1957) adapted the Heaf MP test to the brucellin test and, given a strain-specific, nonagglutinogenic antigen, this technique could be useful diagnostically and epidemiologically. Interpretation of the test by any technique is at present doubtful.

Dermal sensitivity occurred in $10-25 \%$ of the United States population (McCullough, 1955) and is greater in occupationally exposed persons. In this country Brodigan and her co-workers (Brodigan, McDiarmid, Mann and Skone, 1961) found dermal sensitivity in $17 \%$ of children in rural schools, who drank raw milk.

The present 'brucellin' of the Public Health Laboratory cannot claim any of the desirable characteristics enumerated and the time seems appropriate for an investigation by a pharmacology firm to obtain a more sophisticated product.

Cross-relation between Tuberculosis and Brucellosis as a Reason for Greater Susceptibility to Brucella Organisms. A factor which might be of epidemiological significance and lead to a greater susceptibility to smaller doses of brucella organisms depends on the role of the mononuclear cells in the immunity mechanism against tuberculosis and brucellosis. An interesting but apparently neglected original observation by Pullinger in 1936 provides a possible reason for an increase in the number of recognized cases of brucellosis in people drinking raw milk and, therefore, in women and children who drink more milk than men. Pullinger noted the difficulty in isolating $B r$. abortus from 'dirty' milk, due to the presence of tubercle bacilli. Simultaneous inoculation of tubercle bacilli and $\mathrm{Br}$. abortus resulted in the latter being less able to establish infection than when injected alone; a generalized resistance to $\mathrm{Br}$. abortus was shown to exist by injecting the organisms on opposite sides of a guinea-pig. Pullinger suggested that the mononuclear cell reaction stimulated by the tubercle bacilli destroyed the $\mathrm{Br}$. abortus.

Rainsford (1933) had found, in studying brucella infection in Malta (mainly Br. melitensis), an increase in mononuclears to indicate a good prognosis, while early stages of the disease showed a deficiency of mononuclears. Further early observations on the mononuclear cells in $\mathrm{Br}$. melitensis infection were made by Munger (1941). He found leucopenia with relative lymphocytosis and slight monocytosis.

In demonstrating the intracellular multiplication of Br. abortus in mononuclear cells, Pomales-Lebrón and Stinebring (1957) have found that in Br.abortusimmune phagocyte systems the multiplication of the organisms was significantly restricted, and a still unidentified serum factor is stated by Elberg, Schneider and Tong (1957) to be responsible.

According to Elberg and his co-workers (1957), inhibition of bacterial multiplication ultimately resides in a specific cellular activity potentiated by a non-specific serum system. The protection from antibody-complement systems and from antibiotics afforded by the phagocytes to the brucella is well known. 'Immunity' implies that the mononuclear phagocytes have an ability to retard if not to prevent bacterial multiplication in the presence of factors active only in hyper-immune sera. The action of the serum factor enhances the ability of the immune mononuclear cell to resist destruction by ingested bacilli. The specificity of cellular resistance is not strict; it is operative simultaneously against mycobacteria as well as brucellae, irrespective of which is used to immunize the animals. Provided the organism is an intracellular parasite, the mononuclears are important. The serum immunity factor necessary for the mononuclear to display activity, on the other hand, can be induced by any antigenic material, bacterial or otherwise.

Elberg and Meyer (1958) found that animals immunized against tubercle bacilli produced mononuclear cells and were resistant to the destructive action of tubercle as well as brucellae. They concluded that much of the resistance to brucella was nonspecific.

Ralston and Elberg (1960) described a lysozymelike material from rabbit monocytes that acts on glycine-treated brucellae to cause lysis and death.

Elberg et al. (1957) demonstrated a non-specific element in the resistance of monocytes derived from immunized rabbits. Vaccination by BCG or by an effective anti-brucellosis reagent induced protection in either case against both mycobacterium tuberculosis and Br. melitensis, when studied by the monocyte culture method. Bekierkunst and Sulitzeanu (1958) demonstrated that in mice also resistance to $\mathrm{Br}$. abortus 2308 could be induced by $B C G$ vaccination.

Thus the mononuclears have been shown conclusively to be of significance in defence against brucellosis. The implications of this fact are clear. With a falling tuberculin positivity rate in childhood and in the general population, there would also be 
less resistance to $\mathrm{Br}$. abortus ingested, so, though fewer people are exposed, more will have clinical disease, even though perhaps the dose of organisms is also smaller. Consequently, a useful study would be to demonstrate any correlation between the tuberculin test and the brucellergen sensitivity-they should be negatively correlated. Blocking antibodies and positive agglutination to brucellae should be negatively associated with the positive tuberculin test also. The impression that more clinical cases appear than before for a given stimulus is supported by the family outbreak of clinical cases reported by $R$. C. McLeod (1960, personal communication), which is distinctly unusual in the records of $\mathrm{Br}$. abortus infection in this and other countries. (See childhood case survey.)

Angle and his co-workers had, in 1938, noted the absence of positive correlation between positive brucellergen and positive tuberculin reactions. Apparently he had been expecting a positive correlation and therefore reported its absence in his results. However, his figures do show some negative correlation between the two tests, which might be anticipated if the mycobacterium can elicit a stronger mononuclear response than the brucella. Those with tuberculin sensitivity (without active tuberculosis) would probably more readily overcome a subsequent brucella infection and destruction of the invading brucella would avoid brucella sensitization.

Therapy. Spink's (1960) paper on the current status of therapy of brucellosis in human beings is authoritative. He states that the tetracycline drugs -chlortetracycline hydrochloride, oxytetracycline hydrochloride, or tetracycline hydrochloride, constitute the treatment of choice in doses of $500 \mathrm{mg}$. every six hours for a minimum of 21 days, and repeated if tolerated within six to eight weeks if there is a relapse. This is not unusual, particularly with $\mathrm{Br}$. melitensis. In more severe cases streptomycin should be given i.m. 1 to 2 g. for 14 days, simultaneously with the tetracycline drug. These doses are for adults.

Several relapses may occur before recovery and Spink thinks it doubtful if more than three courses of antibiotics are beneficial except rarely when suppuration is present. He also discusses the indication for corticosteroid therapy and does not consider brucella vaccines of value in treatment.

Dalrymple-Champneys (1960) has emphasized that penicillin is not of value in treatment.

\section{II: A Series of 17 Cases}

Estimates of the incidence of brucellosis in England and Wales range from 100 to 1,300 per annum, and childhood cases account for about $10 \%$ of the total. The infection can be unpleasant, can cause complications and can occasionally be fatal in children as well as in adults.

$B r$. abortus is the main member of the brucella group established in animals in this country. $\mathrm{Br}$. melitensis variants are increasingly being reported in cattle, but so far appear to be of low virulence, and no human cases attributable to them have been reported. Only one case of Br. suis and two cases of $\mathrm{Br}$. melitensis have been reported (Williams, Entwistle, Masters and Woods, 1957; Broadbent, 1931; O'Doherty, 1959). These three cases, however, occurred in children.

Recently, local surveys of human and animal brucellosis have shown that cases recognized are constant over the years, that raw T.T. milk and raw non-T.T. milk is often the source, and that rural areas with series of human cases have a correspondingly high level of infection in animals, as shown by the levels of milk and herd infection (Bothwell, 1960a, b, c; McDiarmid, 1960). National figures for cases reported to the Public Health Laboratory Service also show little change from year to year and deficiencies and inadequacies in the legislation are impediments to eliminating the disease (Bothwell, 1961).

The Ministry of Agriculture and Fisheries has recently completed a national survey of brucellosis in milking herds. It is to be hoped that an eradication policy will follow so that in due course both modes of infection for man-infected milk and contact with infected animals-will be removed. Until such an eradication programme has been completed, human cases, including children, will continue to occur.

The 17 childhood cases of brucellosis reported here formed part of a series consisting of 61 cases of all ages admitted to hospital between 1940 and 1958 (Bothwell, 1960a).

\section{Case Reports}

Case 1. July 1940. Boy, aged 11 years, who lived in a village, had evening rise of temperature, from $99^{\circ} \mathrm{F} .\left(37 \cdot 2^{\circ} \mathrm{C}\right.$.) to $101 \cdot 5^{\circ} \mathrm{F} .\left(38 \cdot 6^{\circ} \mathrm{C}\right.$.), for six months before admission to hospital, on one occasion associated with a painful leg. For three weeks before illness he had been drinking raw milk. No other signs were elicited. W.B.C. 10,900 , polymorphs $17 \%$, lymphocytes $70 \%$. Titre $\mathrm{Br}$. abortus $1 / 1,000$. Guinea-pig inoculation positive (blood); culture sterile; skin test positive; treated by brucellin. He stayed in hospital for three weeks. The milk supply was not investigated.

Case 2. June 1941. Girl, aged 9, lived on the outskirts of a small country town. She was admitted to hospital with pyrexia, and was found to have a palpable 
liver and spleen. W.B.C. 5,000, lymphocytes $28 \%$. Titre $1 / 2,500$. She was in hospital for three months. There was no information about the milk supply.

Case 3. February 1943. A boy, aged 10, who lived in a country town. Parents not farming but had lived on a farm until January 1943. For 10 days before admission to hospital he had had headache and remittent fever of $99^{\circ} \mathrm{F}$. $\left(37 \cdot 2^{\circ} \mathrm{C}\right.$.) to $105^{\circ} \mathrm{F}$. $\left(40 \cdot 6^{\circ} \mathrm{C}\right.$. $)$. W.B.C. 8,000 , polymorphs $39 \%$, lymphocytes $61 \%$. Titre $1 / 1,000$. He was treated with brucellin, and temperature subsided after 36 hours. He remained in hospital for two months. Drank raw milk but no follow-up of milk supply was carried out.

Case 4. August 1943. A boy, aged 10, who lived in a city, had had pyrexia for three months and a swollen right knee joint for two days. The spleen was palpable. W.B.C. 6,000 , polymorphs $26 \%$, lymphocytes $71 \%$. Titre 1/2,500. He recovered without specific therapy. He was in hospital for six weeks. The possibility of rheumatic fever was considered. He had been in contact with a sick goat. No follow-up of animal infection was carried out.

Case 5. 1949. A boy, aged 5, who lived in a village (his father was a farm worker) had been listless for five weeks before admission. His temperature was $101^{\circ} \mathrm{F}$. $\left(38 \cdot 3^{\circ}\right.$ C.) and his spleen was palpable. W.B.C. 6,000 , polymorphs $31 \%$, lymphocytes $64 \%$. Titre $1 / 1,000$. Possible diagnoses considered were tuberculosis, typhoid, salmonella infection and leukaemia. No specific treatment was given. He was in hospital for 11 days. There was no follow-up of the milk supply.

Case 6. May 1950. A girl, aged 13, who lived in a village. Before admission she had a sore throat, malaise and severe frontal headaches and pyrexia for four days. History of pyrexia of unknown origin every few years since the age of 5 years. W.B.C. 5,000 , polymorphs $32 \%$, lymphocytes $46 \%$, monocytes $16 \%$. Neutrophil leucocytosis. Titre $1 / 125$, then $1 / 250$. She was thought to have a urinary infection or tonsillar infection. At the age of 3 she had a tonsillectomy. She was in hospital for 52 days, and was treated with sulphonamide and antibiotics. She drank raw milk.

Case 7. March 1951. A girl, aged 9, who lived in the country where her father was a landowner, before admission had had nausea and abdominal pain for 10 days. Examination revealed conjunctival suffusion, headache, fever, pain in calves of legs, cough and anorexia. There were large palpable glands in submandibular, axillary and inguinal areas. She developed measles after admission. Titre $1 / 500$. She was treated with antibiotics, and was in hospital for three days. She was brought up on a farm and drank raw milk up to a month before admission.

Case 8. June 1951. A boy, aged $4 \frac{1}{2}$ years, lived in a country town; his father was an executive. For two weeks he had had general malaise and slight fever, with enlarged left occipital glands. W.B.C. 6,200, polymorphs $34 \%$, lymphocytes $58 \%$, monocytes $6 \%$. Titre $1 / 20,000$. He was treated with antibiotics, and was in hospital for four days. In March 1952 he had pain and limitation of movement in hip joint, with fever and malaise, which appears to have been a further episode. Further agglutination has not been done.

Case 9. June 1953. A boy, aged 13, who lived in a village. For six weeks before admission he had been febrile in the evenings, and had frequently stayed away from school. Eight months before admission he had an episode of fever. Titre $1 / 80$, then $1 / 125$. He was in hospital for one month and was treated with antibiotics.

Case 10. August 1953. A youth, aged 15 years, lived in a country town, and had much general vague illness in 1953: swinging fever, weakness, sweats, sore throat, pain in buttocks, and before admission pyrexial haemoptysis. There was slight enlargement of left hilar glands. W.B.C. 13,000. Slight neutrophil leucocytosis. Titre 1/150. Antibiotic therapy. He was in hospital one month. Developed tuberculous right hip joint in 1956. Right sacro-iliac joint fused in 1957.

Case 11. May 1955. A girl, aged 4 years, lived in a village; her father was a cowman. She presented with jaundice, ? infective hepatitis. Subsequently she was in hospital for considerable periods in 1955, 1956 and 1957, often developing ascites and liver failure. Enlarged liver and signs of diminished liver function continued through these three years. Titre $1 / 1,000$ in September 1955. Positive brucellin test, negative culture. She appeared to respond to antibiotics in each relapse in which she became pyrexial. Since there was no known contact with infective hepatitis, the possibility of serum jaundice was considered; also that diagnosis might be primarily infective hepatitis complicated by brucellosis. Cirrhosis of liver still present in 1957 but jaundice and ascites gone. She drank raw milk, but no follow-up of supply carried out though the herd was known.

Case 12. January 1956. A boy, aged 5 years, lived in the country, where his father was a publican. For three weeks he had intermittent pyrexia and anorexia. W.B.C. 6,000 , polymorphs $47 \%$, lymphocytes $50 \%$. Titre $1 / 250$. He was treated with antibiotics, and was in hospital for five days. The symptoms of pyrexial nature dated back for two years to 1954, and he had been admitted to hospital in 1955. In March 1956 he was admitted again with a vague joint condition, and spent nine weeks in hospital. He drank T.T. milk. About 18 months after his illness, a ring test on the raw T.T. milk was positive ++ , but a subsequent guinea-pig test was negative.

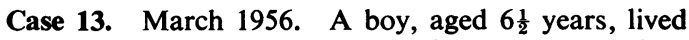
in the city; his father was a Thames Conservancy worker. For three weeks he had fever, listlessness, fatigue, pain in back and side, distended abdomen and enlarged spleen. 
W.B.C. 2,800 , polymorphs $46 \%$, lymphocytes $48 \%$. Titre 1/1,000. Positive culture. He was treated with antibiotics, and was in hospital for eight days. Glandular fever was thought possible. He drank T.T. milk; milk supply was investigated; abortion in herd but no positive result obtained on one milk testing series.

Case 14. May 1956. A boy, aged 5 years, lived in a village; his father was a civil servant. For three weeks he had vague abdominal ache, with pyrexia for 16 days (temperature $104^{\circ} \mathrm{F}$. $\left(40^{\circ} \mathrm{C}\right.$.)); red throat, lymphadenopathy. He developed a macular rash on arms and legs and the liver was palpable. W.B.C. 6,400, polymorphs $50 \%$, lymphocytes $44 \%$, and monocytes $6 \%$. Titre $1 / 2,560$. He was treated with antibiotics, and was in hospital for two weeks. He drank raw milk from a local herd, T.T. Guernsey (a show herd) stated to have had no abortion for 10 years. Not tested for Br. abortus.

Case 15. September 1957. A girl, aged 7 years, who lived in a village (her father was a farm worker), was admitted with a three-week history of tiredness and listlessness; there was some sweating and abdominal pain. She developed bruising in both iliac fossae and had an enlarged liver. General lymphadenopathy. She was thought to have leukaemia clinically. Then positive $B r$. abortus agglutinin + to $1 / 250$. Culture negative. Lymphocytosis. Responded initially to antibiotics. Neutropenia and thrombocytopenia developed. Marrow puncture showed no evidence of leukaemia. She deteriorated, showing persistent lymphadenopathy, enlargement of liver and spleen, and bilateral parotid enlargement. Purpura, headaches, abdominal pain, vomiting, haemorrhage. A biopsy showed bone marrow replaced by tumour cells. She died 11 weeks after admission. Autopsy showed petechial haemorrhages in intestine, and altered blood in stomach. Spleen enlarged $\times 5$. Large lymph nodes in neck, axillae, mediastinum and mesentery, and coeliac axis, inguinal region. The cause of death was lymphosarcoma.

The role of $B r$. abortus in this case is problematical. A titre of $1 / 250$ would normally be diagnostic of brucellosis. The symptoms and response to antibiotics would have been consistent with brucellosis, but also the symptoms and remissions of temperature may have been due to a reticulosis. This child drank raw milk-cows' and goats'. The goats' milk was cultured but found negative. The cows' milk was not investigated, the goats' milk having been thought the most likely source. The herd of animals was not available for testing two years later as it had been broken up. It is interesting that the other members of the family did not have positive $\mathrm{Br}$. abortus agglutinins in the serum. If the patient's titre had simply been incidental and due to exposure to infected milk without causing manifestations of infection, other members of the family might have been expected to have positive reactions also, but they did not.

Case 16. November 1957. A boy, aged 5 years, lived in a village; his father was a bank cashier. For five days he vomited, and had vague abdominal pains, loss of appetite, pyrexia. One week before admission he developed a rash on his chest and back, legs and arms, but not face. He was found to have a congested throat and discrete and enlarged glands in posterior cervical triangle Titre 1/125. W.B.C. 13,000. Neutrophil leucocytosis. Temperature $101-102^{\circ}$ F. $\left(38 \cdot 3-38 \cdot 9^{\circ}\right.$ C.). Gastritis, mesenteric adenitis and tuberculosis were considered in the early stages. He had had raw milk from time to time previously, and before that the usual supply had been raw. He had a previous, similar episode in 1955.

Case 17. November 1958. A boy, aged 11 years, lived in a village; his father was a farm worker. He had a temperature of $104^{\circ} \mathrm{F}$. $\left(40^{\circ} \mathrm{C}\right.$. $)$, sore throat, headache, and pains in head and neck. No response to penicillin and sulphonamides. Pyrexia continued, together with adenitis of neck, axillae and groin. Persistent low-grade pyrexia of $99-100^{\circ} \mathrm{F}$. $\left(37 \cdot 2-37 \cdot 8^{\circ}\right.$ C. $)$ W.B.C. 6,000 , normal differential. Titre $1 / 80$ on November 7 , and $1 / 20,000$ on November 15 . He was in hospital for five days, and discharged before titre became positive. Other possibilities were considered, i.e. upper respiratory infection, glandular fever and tonsillitis. He was admitted again in 1959 with aching thighs and calves and low energy. There were only occasional spikes of temperature in hospital and internal strabismus when tired. He was treated with antibiotics. He drank raw milk at home; abortion in the T.T. herd supplying the milk; the herd was sampled, but tests were negative, probably because udders were being injected with antibiotics.

\section{Comments on Case Histories and Complications}

In 11 of these cases the illnesses were mild and of short duration, but in four there were relapses, one had hepatitis with jaundice, ascites and cirrhosis, and in one fatal case the role of brucellosis was not clear as the diagnosis at autopsy was lymphosarcoma.

Of interest in this connexion is a recent report by Mikulowski and Rogalska-Chrzanowska (1961). They reported a typical clinical case of undulant fever in a child of 5 years (titre 1/500); lymphadenopathy, hepatomegaly, splenomegaly, anaemia, leukopenia and neutropenia developed, followed by pseudoleukaemic bone marrow with $11 \%$ myeloblasts and mitotic cells: recovery occurred after aureomycin and streptomycin.

Diagnosis was uniformly by positive agglutination, only one having a positive blood culture, but blood culture had not been tried intensively.

Fever was the presenting symptom in eight cases, which is similar to the usual mode of presentation in adults. The pattern of pyrexia was irregular in nine, remittent in five, undulant in two, and the pattern was not known in one. Three had nausea with abdominal pain as the predominant features 
TABLE 1

PRESENTING SYMPTOMS AND ALTERNATIVE DIAGNOSES

\begin{tabular}{|c|c|c|c|}
\hline $\begin{array}{l}\text { Presenting } \\
\text { Symptoms }\end{array}$ & No. & $\begin{array}{l}\text { Alternative Diagnoses } \\
\text { Considered }\end{array}$ & No. \\
\hline Fever & 8 & Tuberculosis & 3 \\
\hline $\begin{array}{l}\text { Nausea and abdominal } \\
\text { pain }\end{array}$ & 3 & $\begin{array}{l}\text { Tonsillitis } \\
\text { Glandular fever }\end{array}$ & $\begin{array}{l}2 \\
2 \\
2\end{array}$ \\
\hline Tiredness, listlessness & 3 & $\begin{array}{l}\text { Typhoid fever } \\
\text { Upper respiratory infection } \\
\text { Urinary infection }\end{array}$ & $\begin{array}{l}1 \\
1 \\
1 \\
1\end{array}$ \\
\hline Sore throat & 2 & Gastritis & i \\
\hline Jaundice & 1 & Mesenteric adenitis & \\
\hline
\end{tabular}

and two had sore throats; in these five cases it is unlikely that brucellosis would be considered as the diagnosis.

One child had had a previous febrile episode, two years before; one had a second attack of tiredness and aching thighs and legs about a year after the original attack. Two children had a subsequent episode of pain and limitation of movement in a joint about nine and three months after the original illness, though this appears to have cleared up without permanent effect after antibiotic treatment; in one of these episodes, the child had a negative titre in hospital and this only became positive after discharge, giving the clue to the diagnosis. One child had a macular rash on the arms and legs, and another an erythematous rash on chest, back, legs and arms one week after admission.

The difficulty of diagnosis with the various symptoms reported is shown by the alternative diagnoses suggested (Table 1).

Hospitalization Time. Ten cases were in hospital for periods up to one month; four between one and three months; two between three and six months; and one over six months.

White Blood Counts. The total white cell counts showed two leucopenia, three leucocytosis and 11 within normal limits.

The differential white cell counts were as follows: two leucopenia (both relative lymphocytosis); three leucocytosis (two with polymorph preponderance, one lymphocytosis); 11 within normal limits (nine relative lymphocytosis, one with $92 \%$ polymorphs, $8 \%$ lymphocytes, and one normal).

Glands, Spleen and Liver Enlargement. There were seven cases with enlarged glands recorded, and of these, two also had enlarged spleen and liver; in three cases the spleen alone was enlarged.

The agglutination titres ranged from $1 / 125$ to $1 / 20,000$, but there was no apparent relation between the height of the agglutination titre, the presence of palpable spleen, liver or glands, the blood picture absolute or differential, and the severity of the symptoms or duration of illness.

Distribution and Proportion of Children in Series. The distribution of childhood cases, and of the age and sex of the childhood cases are shown in the Figure. These cases do not represent all the childhood cases admitted to hospital, but only those where the existence of diagnostic indices resulted in finding the notes.

The number of children in the second 10 years is a little higher (13 to four) and there is a higher proportion of females in this second period, but this difference is probably due to better indexed hospital records in later years.

The high proportion of children in this series of cases admitted to hospital may not correctly indicate

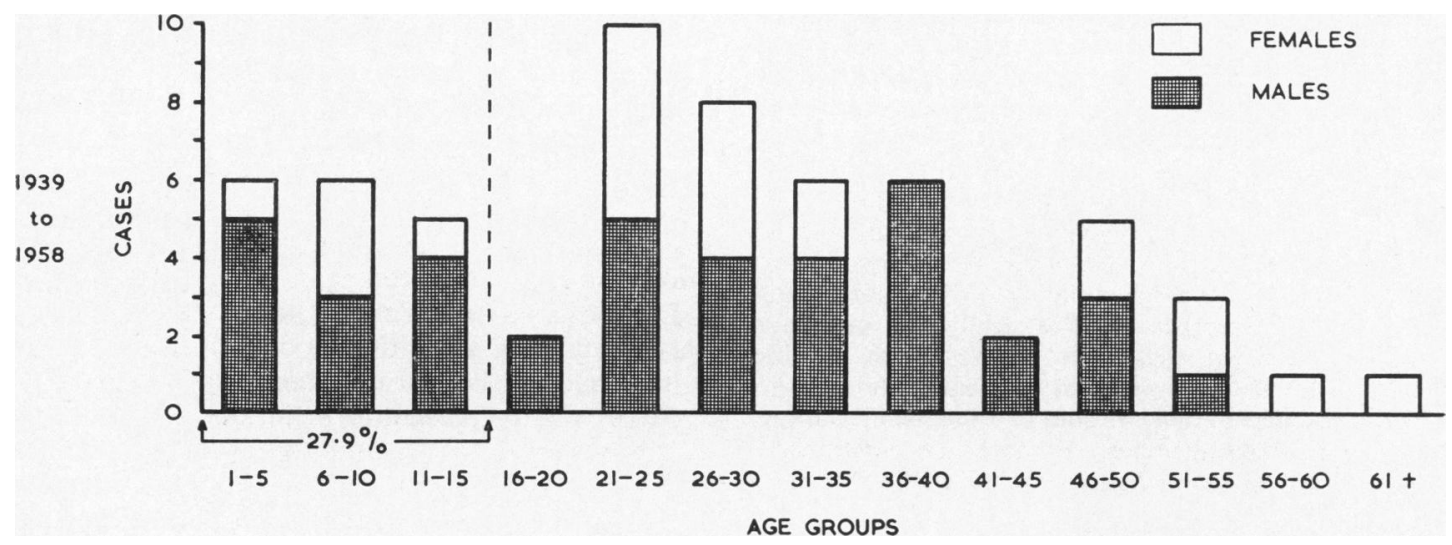

Figure.-The proportion of children accounted for almost one-third of all cases. This proportion of children is much higher than is usually described. 
the incidence of brucellosis in childhood, since the criteria for admission to hospital for children and adults may differ in this area from others. Also, since brucellosis is not a notifiable disease, even when recognized, there will be no record of cases treated outside hospital. In the period in question, for example, there were other childhood cases described in the same area by Elkington et al. (1940). Admitted to a school sick bay, they do not figure in the present series; if they had done so they would have raised further the percentage of children in the whole series. Accurate statistics of brucellosis incidence at any age are, however, non-existent, and the series here is very small.

Greater paediatric awareness and interest in this disease in the area probably increased the proportion of children in this series. If it is a correct interpretation of the situation that S.19 vaccination of animals has reduced abortion and therefore possible contact infection, then an apparent increase in the numbers of women and children (the greater milkdrinking segments of the population) would occur, particularly if better diagnosis is occurring. If new cases are to be found, then childhood and female cases might be expected to be more frequently diagnosed.

Sex. The sex ratio was 2.4 male to 1 female. It is usual to ascribe the male preponderance of brucellosis to increased risk of contact by occupational exposure in males. Only two of the males in this series lived on farms and might have had greater opportunity for contact infection for that reason.

The parents of these children had widely varying occupations, though there were more from farming than any other single group (Table 2). In the two unknown cases (early cases) in the series, the children did not live on farms.

The value of the human case as an index of infection in cattle needs wider recognition. The suspected milk supply should be examined in detail to locate the infected animals, but in the cases described in the present series, this had rarely been considered. During subsequent investigations of the milk supplies, there was an impression among farmers and public health personnel that because the animals had been vaccinated with S.19 they could not be the source of infection. The facts are that abortion need not be present in an infected animal; and even in one that has been vaccinated, an asymptomatic udder infection may persist for years, and indeed udder infection is three times commoner in infected cows than uterine infection (Kerr, 1960; McDiarmid, 1960).
TABLE 2

PARENTAL OCCUPATION

\begin{tabular}{c|c}
\hline Occupation of Parent & Number of Child Cases \\
\hline Farm workers & 4 \\
Labourers & 2 \\
Fishmonger & 1 \\
Publican & 1 \\
Landowner & 1 \\
Civil servant & 1 \\
Coach driver & 1 \\
Factory worker & 1 \\
Engineer & 1 \\
Bank employee & 1 \\
Executive & 1 \\
Unknown & 2 \\
\hline Total .. & 17 \\
\hline
\end{tabular}

The persistent occurrence of brucellosis in childhood may to some extent reflect the widespread disorientation of the public in regard to what is safe and what is clean milk. Much publicity has created the general idea of the safety of T.T. milk, which is nearly always true in regard to tuberculosis, but there is no reason why T.T. milk should be better than any other in regard to brucellosis. Of the cases described here, 13 can be attributed to drinking infected milk (in four recent cases from T.T. herds); two other cases were more likely than not to have been milk infections also, since they had never lived on a farm. The two remaining cases may have been due to contact with infected material, since an undisclosed contact might have occurred. Contact is difficult to prove, and infected milk is more readily demonstrated as a cause of infection, and to this extent the figures may be biased in favour of milk rather than contact.

All but one of the 17 children in this series (12 boys . and five girls) lived in the country or in small country towns; such a rural preponderance of cases allows of greater opportunities to drink raw milk, either in T.T. bottled form or straight from the cow on the farm, and also of course implies greater opportunity for contact with infected material from animals.

Since the disease has always been recognized as most difficult to diagnose clinically, some assistance in its identification would be obtained if general practitioners knew where there were infected herds on farms retailing raw milk or where the farm staff consumed raw milk.

Even though they may represent only a fraction (say one in 10) of the real incidence of brucellosis in the area, 17 cases (or 170) of a rare childhood disease over 20 years are statistically insignificant. Their importance lies in their incapacitating effect and in the fact that they are all cases of an illness which is entirely avoidable. If we cannot remove this condition with well-understood aetiology, what 
prospects are there for removal of the more statistically significant but aetiologically baffling diseases?

\section{Summary}

Brief details of 17 cases of brucellosis in children up to 15 years, admitted to hospital between 1940 and 1958, are discussed. The diagnosis in each of these cases is the final one arrived at in hospital and usually based on positive agglutination and the clinical picture; only one had a positive blood culture. Remittent or irregular pyrexia was seen in 14 and 'undulant' pyrexia in two.

Attention is drawn to the continuing important role of infected raw milk in the aetiology of this disease in childhood; 13 cases appeared to be due to drinking raw milk, in four of these the milk was tuberculin-tested.

The disease was mild in 11 cases, prolonged and debilitating in four cases, and was associated with cirrhosis in one case and a fatal issue in one other. The association of brucellosis with cirrhosis of the liver in a child does not appear to have been reported previously, though there is nothing surprising in such an event. The brucellosis diagnosis in both the latter cases depends on agglutination of $1 / 1,000$ and $1 / 250$ and not on culture of the organism, however.

Children from 0 to 15 years account for approximately $30 \%$ of hospital admissions for brucellosis in the Oxford region. Reasons for this are discussed. Progressively improving recognition may be a factor in the higher percentage of children in the general series from which these 17 cases are drawn than is usual in series of brucellosis cases.

It is well known that the disease is difficult to recognize in mild cases and general practitioners should be informed about infected sources. This is a task for public health departments working in liaison with their veterinary colleagues, but the absence of notification of human and animal brucellosis impedes this kind of progress.

My thanks are due to the hospitals and consultants who kindly allowed me to refer to and quote from their case records.

\section{REFERENCES}

Angle, F. E., Algie, W. H., Baumgartner, L. and Lunsford, W. F (1938). Skin testing for brucellosis (undulant fever) in school children. Ann. intern. Med., 12, 495.

Barrett, G. M. and Rickards, A. G. (1953). Chronic brucellosis. Quart. J. Med., 22, 23.

Beattie, C. P., Smith, J. and Tulloch, W. J. (1935). Undulant fever in Scotland. Lancet, 1, 1427.

Behrendt, H. (1949). Diagnostic Tests for Infants and Children. Interscience, New York.

Bekierkunst, A. and Sulitzeanu, D. (1958). Induced resistance of mice to injection with brucella abortus 2308 through vaccination with BCG. Nature (Lond.), 182, 883.

Black, R. A. (1937). Brucella melitensis meningitis in an infant. Arch. Pediat., 54, 702.
Bothwell, P. W. (1960a). Brucellosis in the Oxford region. Med. Offr, 103, 85 .

(1960b). Brucellosis: an anachronism in public health. Vet. Rec., 72, 425.

(1960c). Epidemiology and prevention of human brucellosis. ibid.,77, 933.

(1961). Endemiology of brucellosis in rural areas. Publ. Hlth, $75,274$.

Branwood, A. W. (1952). Some unusual manifestations of abortive fever. Edinb. med. J., 59, 591.

Braude, A. I. (1955). Brucellosis: epidemiology and treatment. $G P, 11$, no. 3, pp. 75-84.

Broadbent, W. (1931). Undulant fever acquired from a goat in England. Lancet, $1,76$.

Brodigan, M., McDiarmid, A., Mann, P. G. and Skone, J. F. (1961). Brucellosis - an island epidemiological study. Brit. med. J., 2, 1393.

Bürki, F. and Fey, H. (1953). Blockingtest und modifizierter Coombstest in der Serodiagnostik der menschlichen Brucellosen. Schweiz. Z. allg. Path., 16, 945. (Cited by Wallis, 1959.)

Burnet, E. (1922). Recherches sur la fièvre Méditerranéenne. Arch. Inst. Pasteur Afrique Nord., 2, 187.

Calder, R. M., Steen, C. and Baker, L. (1939). Blood studies in brucellosis. S. Amer. med. Ass., 112, 1893 .

Castaneda, M. R. and Guerrero, I. G. (1946). Studies on the leucocytic picture in brucellosis. J. infect. Dis., 78, 43 .

Conway, H. (1949). Lymphadenopathy in brucellosis. Brit. med. J., $2,787$.

Cozzolino, O. (1915). La febbre melitense o mediterranea o ondulante nei bambini. Pediatria (Napoli), 23, 561. (Cited by Hagebusch and Frei, 1941.)

Cruickshank, J. C. (1956). Incomplete antibodies in experimental brucella infection. J. Hyg. (Lond.), 54, 562.

and Stevenson, G. A. (1942). Undulant fever: a small outbreak in a girls' school. Brit. med. J., 1, 522 .

Dalrymple-Champneys, W. (1950)." Undulant fever: A neglected problem. Lancet, 1, 429.

(1952). Undulant fever (brucellosis), Brit. Encyclopaedia Med. Practice, 12, 423.

(1960). Brucella Infection and Undulant Fever in Man. Oxford University Press, London.

Davies, J. E. (1957). Chronic brucellosis in General Practice. Brit. med. J., 2, 1082.

Debono, J. E. (1943). In Brucellosis in Man and Animals, ed. I. F. Huddleson, 2nd ed. Commonwealth Fund, New York.

Dooley, P. (1931). The incidence of undulant fever in children. Arch. Dis. Childh., 6, 235.

Elberg, S. S. (1958). In Bacterial and Mycotic Infections of Man ed. R. J. Dubos, 3rd ed., chap. 19. Pitman Medical Publishing Co., London.

and Meyer, K. F. (1958). Caprine immunization agains brucellosis. Bull. Wld Hlth Org., 19, 711.

Schneider, P. and Fong, J. (1957). Cross-immunity between brucella melitensis and mycobacterium tuberculosis. J. exp. Med., 106, 545.

Elkington, G. W., Wilson, G. S., Taylor, J. and Fulton, F. (1940). A mild epidemic of undulant fever in a boys' school due to drinking raw milk. Brit. med. J., 1, 477.

Garrod, L. P. (1937). The susceptibility of different bacteria to destruction in the stomach. J. Path. Bact., 45, 473.

Hagebusch, O. E. and Frei, C. F. (1941). Undulant fever in children. Amer. J. clin. Path., 11, 497.

Hall, W. H. (1950). Symposium 3rd Inter-Amer. Congress, Brucellosis, Washington, p. 87. (Cited by Dalrymple-Champneys, 1960.)

- and Manion, R. E. (1953). Comparison of the Coombs test with other methods for brucella agglutinins in human serum. J. clin. Invest., 32, 96 .

Huddleson, I. F. (1943). Brucellosis in Man and Animals, 2nd ed. Commonwealth Fund, New York.

- (1952). Studies in brucellosis, III. Michigan State College.

J. Amer. med. Ass. (1954). Editorial: Standardized brucella diagnostic antigen, 155, 1336.

Jordan, C. F. (1945). Proc. 49th Ann. Mtg U.S. Livestock San. Assoc., p. 185. (Cited by Magoffin, Kabler, Spink and Fleming, 1949.)

(1950). In Brucellosis: A Symposium, p. 101. American Association for the Advancement of Science, Washington.

Kelly, P. J., Martin, W. J., Schirger, A. and Weed, L. A. (1960). Brucellosis of the bone and joints: Experience with 36 patients. J. Amer. me.t. Ass., 174, 347.

Kerr, W. R. (1960). Brucella eradication schemes in Northern Ireland. Vet. Rec., 72, 921.

Leys, D. G. (1943). Abortus fever. Brit. med. J., 1, 187.

Lovell, R. (1951). Infection and resistance in young animals. Lancet, 2, 1097

McCullough, N. B. (1955). Symposium of unusual infections in childhood. Pediat. Clin. N. Amer., 2, 73.

McDiarmid, A. (1960). Surveys of brucellosis in Oxfordshire and in the Isle of Wight. Vet. Rec., 72, 423. 
Magoffin, R. L., Kabler, P., Spink, W. W. and Fleming, D. (1949). An epidemiologic study of brucellosis in Minnesota. Publ. Hlth Rep. (Wash.), 64, 1021

Meyer, K. F. (1950). In 3rd Internat. Congress on Brucellosis, Washington, p. 177. Pan-Amer. San. Bur.

Mikulowski, V. and Rogalska-Chrzanowska, E. (1961). I Ieukemoid reaction in the bone marrow during course of brucellosis in a child. Ann. paediat. 197, 166.

Miles, A. A. and Pirie, N. W. (1939). The properties of antigenic preparations from brucella melitensis. Brit. J. exp. Path. 20,83 .

Munger, M. (1941). A study of the leucocytic picture in brucellosis Tech. Bull. No. 177, Michigan Agric. Exper. Stn, 35.

and Huddleson, I. F. (1939). A preliminary report of the blood picture in brucellosis. J. Lab. clin. Med., 24, 617.

O'Doherty, R. (1959). Brucella melitensis infection of an infant. $J$. Irish med. Ass. 44, 134

Ottosen, H. E. and Plum, N. (1949). A nonantigenic allergic agent for intradermal brucellosis tests. Amer.J. vet. Res., 10, 5.

Paterson, D. H. and Hardwick, C. (1938). Undulant fever in children. Arch. Dis. Childh., 13, 65.

Pennell, R. B. and Huddleson, I. F. (1937). Chemical constitution and biological properties of the endo-antigen of the brucella group of micro-organisms. Tech. Bull. 156, Michigan Agric. Exper. Stn.

Pomales-Lebrón, A. and Stinebring, W. R. (1957). Intracellular multiplication of Brucella abortus in normal and immune monomultiplication of Brucella abortus in normal and immune
nuclear phagocytes. Proc. Soc. exp. Biol. (N.Y.), 94, 78.

Pullinger, E. J. (1936). The influence of tuberculosis upon the development of Brucella abortus infection. J. Hyg. (Lond.), 36, 456 .

Rainsford, S. G. (1933). Laboratory methods of diagnosis of brucella infections. J. roy. nav med. Serv., 19, 1.

Ralston, D. J. and Elberg, S. S. (1960). Action of glycine and a lysozyme-like agent from rabbit monocytes in destruction of brucella. Proc. Soc. exp. Biol. (N.Y.), $104: 464$.
Renoux, G. E. (1953). Some aspects of human brucellosis. WHO/ FAO Agric. Studies, No. 25, p. 61.

Rubenstein, A. D. and Shaw, C. I. (1944). Infectious mononucleosis simulating brucellosis. New Engl. J. Med., 231, 111.

Russell, G. R. (1947). Brucellosis in children. J. Oklahoma med. Ass., 40, 82.

Sabin, F. R. (1923). Studies of living human blood-cells. Bull Johns Hopk. Hosp., 34, 277.

Smith, J. (1951). The epidemiology of undulant fever in the northeast of Scotland, 1929-1950. Hlth Bull. (Edinb.), 9, 57.

Spink, W. W. (1952). In Practice of Paediatrics, ed. J. Brennemann vol. 2, chap. 33. Prior, Hagerstown, Maryland.

- (1954). Family studies on brucellosis. Amer. J. med. Sci. 227,128 .

(1956). The Nature of Brucellosis. University of Minnesota Press, Minneapolis.

(1960). Current status of therapy of brucellosis in human beings. J. Amer. med. Assoc., 172, 697.

Wagner, B. M. and Kuhns, D. M. (1953). Coombs type of antibody (antiglobulin) in brucellosis. Amer. J. clin. Path., 23, 185.

Wallis, H. R. E. (1957). Brucellosis in children. Brit. med. J., 1,617 .

(1959). Brucellosis in England. O'Connor, London.

Williams, T. P., Entwistle, D. M., Masters, P. L. and Woods, A. C. (1957). Brucella suis infection of a child in Eire. Lancet, 2, 1203.

Williamson, B. and Gibson, A.'J. (1931). Undulant fever in infancy. Brit. med. J., 1, 748.

Wilson, M. M. and Merrifield, E. V. O. (1951). The antiglobulin (Coombs) test in brucellosis. Lancet, $2,913$.

World Health Organization (1951, 1953, 1958). Reports on Brucellosis. Wld Hlth Org. techn. Rep. Ser., nos. 37, 67, 148.

Zinneman, H. H., Glenchur, H. and Hall, $W^{\prime}$. H. (1959). The nature of blocking antibodies in human brucellosis. I. Immunol., 83 206. 